\title{
AUTONOMOUS TARGET TRACKING FOR AIRSOFT GUN BASED ON LABVIEW VISION 2015
}

\author{
Syafrizal Syarief ${ }^{1}$ dan Fhyras Ayatullah Rismawa ${ }^{2}$ \\ ${ }^{1,2)}$ Jurusan Teknik Elektro, Politeknik Negeri Jakarta \\ E-mail: ${ }^{1)}$ syafrizal.syarief@elektro.pnj.ac.id
}

\begin{abstract}
Automatic Target Tracking on Airsoft Gun Based on LabVIEW Vision is a system that serves to track the movement of the target which is the target of the airsoft gun. The target that is being targeted is a shooting target that moves on the $X$ and $Y$ axes.

To track the target is done through the mechanism of controlling the angle position in the elevation and azimuth fields using continuous linear control techniques against normal lines $X$ and $Y$. The angular position in the elevation field is limited to $-10^{\circ}$ to $+10^{\circ}$ and azimuth $-45^{\circ}$ to $+45^{\circ}$ with resolution smaller or equal to 0.2 degrees. When the target does not move, the tracking will automatically stop right at the central point of the target, then Airsoft Gun automatically shoots the target, with an effective shooting distance of 1.5 meters.

The target position is identified using LabVIEW Vision based color and pattern recognition methods. The Angle Position Control System used is $P$ (Proportional) Control with a value of $\mathrm{KC}=10, \mathrm{Ti}=0$, and Td = 1x10-6 with the amount of time to reach the set point (sp) of 4.7 seconds.

The percentage error in the position of the angle obtained is $1.38 \%$. The resolution of the angle obtained is $0.08 \circ$. The maximum range of equipment obtained at the angles of $-10 \mathrm{o}$ and $+10 \mathrm{o}$ is $-152.24 \mathrm{~cm}$ and $152.59 \mathrm{~cm}$. We concluded that the standard deviation value obtained from the calculation of the angle value of the actual distance is 0.8 .
\end{abstract}

Keywords: Automatic target, airsoft gun, color and pattern recognition, LabVIEW Vision 2015

\begin{abstract}
ABSTRAK
Penjejak Target Otomatis pada Airsoft Gun Berbasis LabVIEW Vision adalah suatu sistem yang berfungsi untuk menjejak pergerakan target yang menjadi sasaran tembak dari airsoft gun. Target yang menjadi sasaran tembak berupa sasaran tembak (shooting target) yang bergerak pada sumbu X dan $Y$.

Untuk menjejak target dilakukan melalui mekanisme pengendalian posisi sudut pada bidang elevasi dan azimuth menggunakan teknik kontrol linier kontinyu terhadap garis normal $\mathrm{X}$ dan $\mathrm{Y}$. Posisi sudut pada bidang elevasi dibatasi $-10^{\circ} \mathrm{s} . \mathrm{d}+10^{\circ}$ dan bidang azimuth $-45^{\circ} \mathrm{s.d}+45^{\circ}$ dengan resolusi lebih kecil atau sama dengan 0,2 derajat. Ketika target tidak bergerak, maka secara otomatis penjejakan akan berhenti tepat mengarah ke titik sentral dari target, kemudian Airsoft Gun secara otomatis menembak target tersebut, dengan jarak tembak efektif yaitu 1,5 meter.

Posisi target diidentifikasi menggunakan metode pengolahan citra (color and pattern recognition) berbasis LabVIEW Vision. Sistem Kontrol Posisi Sudut yang digunakan adalah Kontrol $P$ (Proportional) dengan nilai $\mathrm{Kc}=10, \mathrm{Ti}=0$, dan $\mathrm{Td}=1 \times 10^{-6}$ dengan besar waktu untuk mencapai set point (sp) sebesar 4,7 detik. Persentase error posisi sudut yang diperoleh adalah 1,38\%. Besar resolusi sudut yang diperoleh adalah $\mathbf{0 . 0 8}^{\circ}$. Jangkauan maksimum dari alat yang didapatkan pada sudut $-10^{\circ}$ dan $+10^{\circ}$ sebesar $-152,24 \mathrm{~cm}$ dan $152,59 \mathrm{~cm}$. Nilai standar deviasi yang didapatkan dari perhitungan nilai sudut terhadap jarak sebenarnya adalah $\mathbf{0 , 8}$.
\end{abstract}

Kata kunci : Penjejak target otomatis, airsoft gun, color and pattern recognition, LabVIEW Vision 2015

\section{PENDAHULUAN}

Teknologi persenjataan yang semakin canggih membuat banyak negara bersaing menciptakan senjata otomatis. Awalnya senjata tersebut menggunakan tenaga manusia yang terjun langsung ke medan perang. Namun, karena teknologi yang semakin berkembang, manusia hanya menentukan objek yang menjadi sasaran tembak pada mesin perang tersebut. Kemudian mesin perang 
tersebut akan mengunci sasaran tembak dan menembaknya dengan cepat. Hal ini tentu dapat mengurangi kerugian materiil dan immateriil yang iakibatkan terjun langsung di medan perang.

Mesin perang tersebut menjadi acuan penulis untuk membuat prototipe alat penjejak target otomatis menggunakan Airsoft Gun berbasis LabVIEW Vision. Prototipe alat ini dibuat dengan menggunakan Airsoft Gun tipe LPEG(Low Power Electric Gun) yang dapat diaktuasi dengan aliran listrik. Alat ini menggunakan kamera sebagai sensor optik yang berfungsi mengambil, memproses dan menjejak sasaran yang telah ditentukan.

LabVIEW Vision sebagai perangkat lunak berisi algoritma-algoritma yang memproses gambar agar menjadi sasaran tembak yang akurat dan menembak dengan efisien.

\section{METODE PENELITIAN}

\section{Perancangan}

Dalam membuat perancangan alat, proses pengerjaannya berawal dari deskripsi alat, cara kerja, spesifikasi, dan diagram blok harus direncanakan dengan baik. Proses perancangan dimulai dengan mendesain seluruh perangkat yang dibutuhkan.

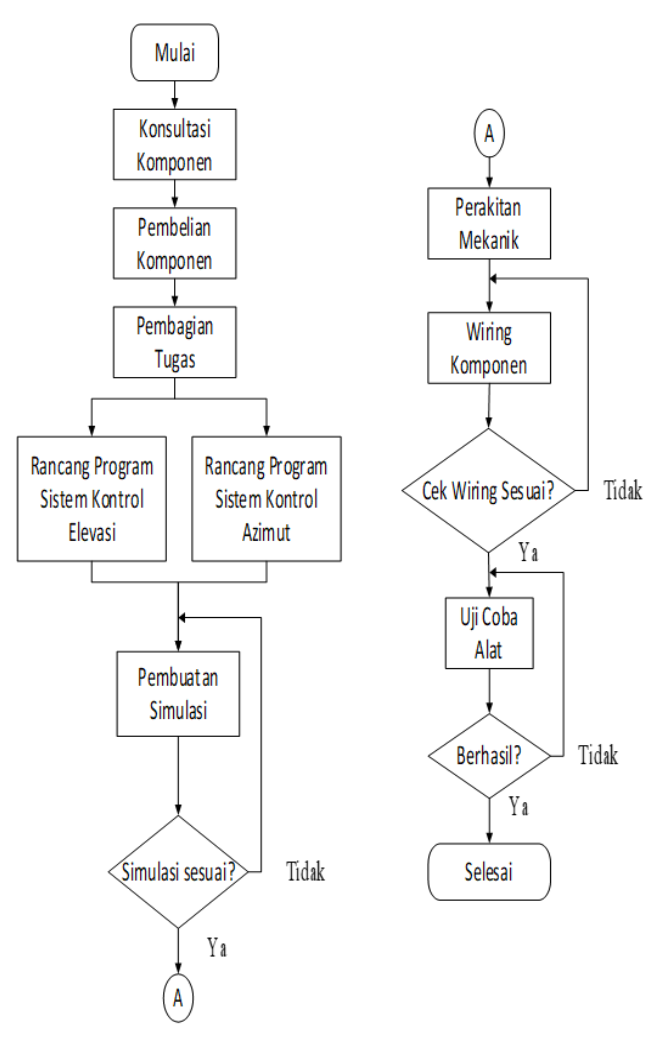

Gambar 1 Skema Perancangan Alatt

\section{Pengujian Sistem Kontrol Elevasi}

Pengujian ini dilakukan dengan metode trial and error untuk mencari nilai Kc, Ti, dan Td. Proses tuning dilakukan dengan menguji alat ini bergerak pada sudut elevasi dan mengubah beberapa variabel yang terdapat pada nilai $\mathrm{Kc}$, Ti, dan Td. Untuk melakukan pengujian dilakukan beberapa tahapan yang dilalui secara berurutan yaitu sebagai berikut.

a) Pengecekan wiring kabel antara sensor dengan kontroler, antar aktuator dengan relay, dan lain-lain. Pastikan input (+) dan (-) tidak tertukar.

b) Mengaktifkan bagian sistem seperti NI DAQ, Quanser Servo Unit dan Quanser VoltPAQ-X1.

c) Buk program sistem pada software LabVIEW 2015.

d) Cek inisialisasi input maupun output pada blok diagram.

e) Klik run pada software LabVIEW 2015. 
f) Setting nilai $\mathrm{Kc}$, $\mathrm{Ti}$, dan $\mathrm{Td}$ sehingga mendapatkan settling time dan response yang stabil dengan menggunakan metode trial and error.

g) Jika sudah stabil, save program dan permanenkan nilai-nilai tersebut menjadi konstan.

h) Export grafik yang dihasilkan antara set point dan Process Value pada percobaan sistem ke Ms.Excel.

i) Ulangi poin keenam sampai poin kedelapan agar mendapatkan hasil pengujian yang tepat pada sistem.

j) Buat tabel dan analisa grafik tersebut hingga mendapatkan nilai steady state.

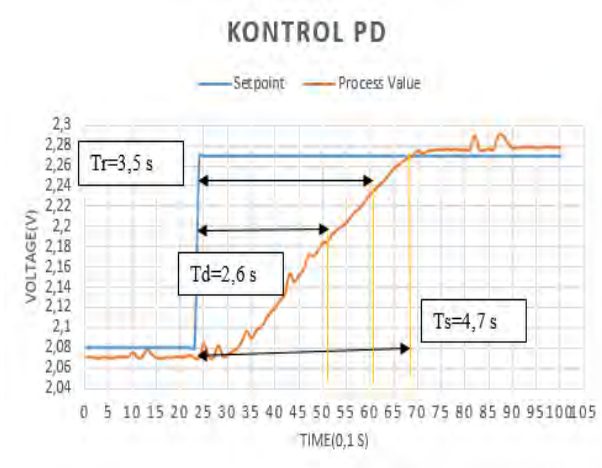

Gambar 2. Kontrol PID

Gelombang yang dihasilkan dari kontrol PD pada gambar 4.1 berdasarkan nilai $\mathrm{Kc}=10, \mathrm{Ti}=0$, dan $\mathrm{Td}=1 \times 10-6$.

\section{Hasil Pengujian.}

Dari hasil pengujian kontrol PI dimana $\mathrm{Kc}=10$, Ti=0, dan $\mathrm{Td}=1 \times 10-6$. Maka diperoleh response transient sepeti dibawah ini , pada gambar 2 tersebut, dipetroleh :

\section{a) Time constant (t)}

Ukuran waktu yang menyatakan kecepatan respon, yang di ukur mulai $\mathrm{t}=$ $0 \mathrm{~s} / \mathrm{d}$ respon mencapai $63,2 \%(\mathrm{e}-1 \times 100 \%)$ dari respon steady state yaitu sebesar 1,3 s.

b) Rise Time (Tr)

waktu yang diperlukan tanggapan sistem untuk naik sampai dengan respon memotong sumbu steady state yang pertama adalah 3,5 detik.

c) Settling Time (Ts)

Waktu tunak respon. Berdasarkan simulasi terhadap sistem, didapatkan waktu tunak adalah 4,7 detik.

d) Delay Time (Td)

waktu yang menyatakan faktor keterlambatan respon output terhadap input, diukur dari $\mathrm{t}=0 \mathrm{~s} / \mathrm{d}$ respon mencapai $50 \%$ dari respon steady state adalah 2,6 detik.

\section{HASIL DAN PEMBAHASAN}

Berdasarkan hasil pengujian kontrol posisi sudut $\left({ }^{\circ}\right)$ dengan menggunakan metode trial and error dan diperoleh kondisi steady state pada saat nilai $\mathrm{Kp}=10$, Ti=0, dan $\mathrm{Td}=1 \times 10-6$, waktu yang dibutuhkan untuk mencapai kestabilan sistem sesuai dengan set point (sp) adalah sebesar 0,5s. Berdasarkan hasil pengujian tersebut maka dapat diketahui nilai pengukuran sudut antara set point (sp) dan proses variable (pv), \% error sudut, serta resolusi sudut. Analisa dari metode tersebut adalah sebagai berikut:

\section{Perhitungan Nilai Persentase Error Posisi Sudut}

Persentase nilai error antara setpoint dengan Process Value dalam besaran sudut yang nyata ditunjukkan pada tabel sebagai berikut.

Tabel 1. Persentase Error Kontrol PD 


\begin{tabular}{ccc}
$\mathrm{SP}\left({ }^{\circ}\right)$ & PV $\left(^{\circ}\right)$ & \%ERROR \\
\hline-10 & $-9,97$ & 0,30 \\
-9 & $-9,07$ & 0,78 \\
-8 & $-7,97$ & 0,38 \\
-7 & $-6,93$ & 1,00 \\
-6 & $-5,95$ & 0,83 \\
-5 & $-4,97$ & 0,60 \\
-4 & $-3,98$ & 0,50 \\
-3 & $-2,98$ & 0,67 \\
-2 & $-2,03$ & 1,50 \\
-1 & $-1,04$ & 4,00 \\
0 & 0,03 & 0,00 \\
1 & 1,06 & 6,00 \\
2 & 2,02 & 1,00 \\
3 & 3,05 & 1,67 \\
4 & 4,05 & 1,25 \\
5 & 5,09 & 1,80 \\
6 & 6,13 & 2,17 \\
7 & 7,03 & 0,43 \\
8 & 8,2 & 2,50 \\
9 & 9,15 & 1,67 \\
10 & 10,1 & 1,00 \\
\hline
\end{tabular}

Dengan mengunakan interval pengambilan data sebesar $30 \%$ dari sudut $-10^{\circ}$ s.d $+10^{\circ}$. Dimana totalnya ada 20 data dalam derajat $\left({ }^{\circ}\right)$. Maka interval tersebut terletak pada data 6 data awal, 6 data tengah, dan 6 data akhir, yaitu : $-10^{\circ}$ s.d $-^{\circ},-2$ s.d $+4^{\circ}$
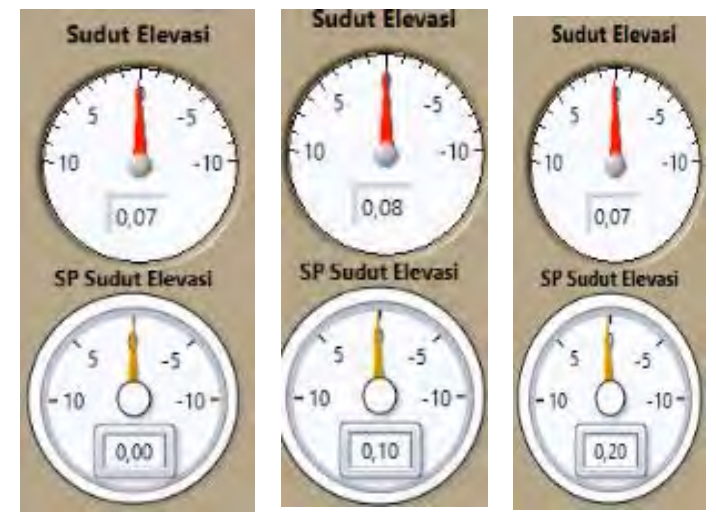

Gambar 3.Dashboard sudut Elevasi

tanpa data $0^{\circ}$, dan $37^{\circ}$ s.d $45^{\circ}$. Perhitungannya dapat dilihat pada persamaan dibawah ini :

$$
\begin{array}{ll}
\text { Error (\%) interval I } & =\frac{\sum \% \text { error }}{\text { banyak data }} \\
& =\frac{3,89}{6} \\
& =0,64 \% \\
\text { Error (\%) interval II } & =\frac{\sum \% \text { error }}{\text { banyak data }} \\
& =\frac{12,67}{6} \\
& =2,11 \% \\
\text { Error (\%) interval III } & =\frac{\sum \% \text { error }}{\text { banyak data }} \\
& =\frac{8,31}{6} \\
& =1,39 \% \\
& =\frac{\sum \% \text { error }}{j u m l a h \text { interval }} \\
\text { Rata-Rata Error (\%) } & =\frac{3,89+2,11+1,38}{3} \\
& =\frac{4,14}{3} \\
& =1,38 \%
\end{array}
$$

Berdasarkan perhitungan nilai error (\%) metode trial and error untuk tunning PID dengan menggunakan parameter Kc dan Td diperoleh hasil rata-rata error (\%) nya sebesar $1,38 \%$.

\section{1) Perhitungan nilai resolusi sudut}

Resolusi merupakan perubahan terkecil dalam nilai yang diukur pada instrumen saat memberi respon atau tanggapan. Resolusi sudut merupakan perubahan terkecil pada sudut yang diukur

.Pada gambar 3 ditunjukkan bahwa perubahan sudut sebesar $0,1^{\circ}$ tidak berpengaruh terhadap nilai Process Value. Pengujian ini dilakukan hingga mencari nilai resolusi yang tepat untuk kontrol sudut elevasi.

Tabel 2. Pengujian Resolusi 0.1

\begin{tabular}{ll}
\hline Set Point & Process Value \\
\hline 0.0 & 0.07 \\
0.1 & 0.08 \\
0.2 & 0.07 \\
\hline
\end{tabular}




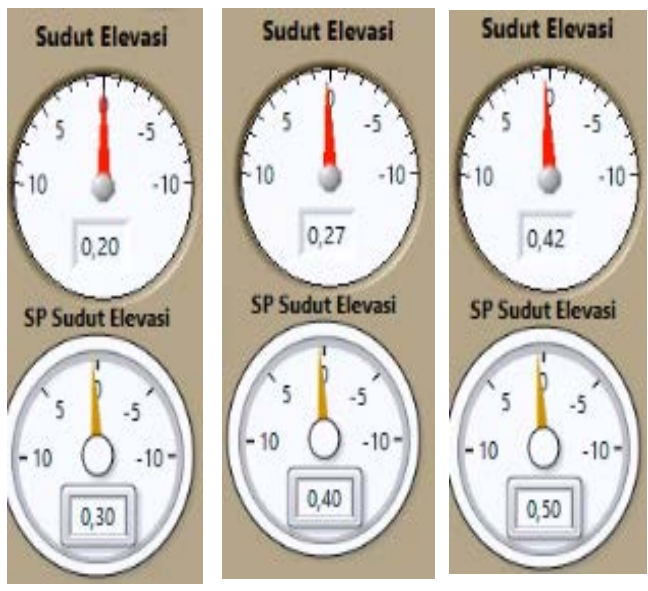

Gambar 4 Pengujian Resolusi 0,2o

Pada gambar 4 ditunjukkan perubahan resolusi sudut sebesar $0,2^{\circ}$. Ini terlihat karena saat setpoint dirubah dari sudut 0,00 ke sudut 0,30 , terjadi perubahan Process Value mendekati nilai setpoint. Selain itu, perubahan sudut terjadi dari sudut $0,2^{0}$ ke sudut $0,5^{0}$.

Tabel 3. Pengujian Sudut

\begin{tabular}{ll}
\hline Set point & Process Valaue \\
\hline 0.3 & 0.20 \\
0.4 & 0.27 \\
0.5 & 0.42 \\
\hline
\end{tabular}

Berdasarkan pengujian untuk resolusi sudut $\left({ }^{\circ}\right)$ dengan merubah besaran sudut $\left(^{\circ}\right)$ pada kontrol sudut elevasi sebesar $0,1^{\circ}$, tidak terjadi perubahan. Kemudian, pengujian dilanjutkan dengan kontrol sudut elevasi sebesar $0,2^{\circ}$ dan terjadi perubahan antara sudut setpoint dengan Process Value. Dapat disimpulkan bahwa resolusi yang mampu bekerja pada sistem kontrol sudut elevasi sebesar $0,2^{\circ}$.
Tabel 4. Pengukuran Sudut Terhadap Jarak.

\begin{tabular}{|c|c|c|c|}
\hline \multirow{2}{*}{ Sudut( $\left({ }^{\circ}\right)$} & \multicolumn{3}{|c|}{ Jarak Sebenarnya(cm) } \\
\hline & a & $b$ & $\mathrm{C}$ \\
\hline 10 & 28 & 150 & 152,59 \\
\hline 9 & 25 & 150 & 152,07 \\
\hline 8 & 22 & 150 & 151,60 \\
\hline 7 & 19,5 & 150 & 151,26 \\
\hline 6 & 17,5 & 150 & 151,02 \\
\hline 5 & 13,5 & 150 & 150,61 \\
\hline 4 & 11,5 & 150 & 150,44 \\
\hline 3 & 8,5 & 150 & 150,24 \\
\hline 2 & 6,8 & 150 & 150,15 \\
\hline 1 & 3 & 150 & 150,03 \\
\hline 0 & 0 & 150 & 150 \\
\hline-1 & $-2,5$ & 150 & $-150,02$ \\
\hline-2 & $-5,5$ & 150 & $-150,10$ \\
\hline-3 & $-8,5$ & 150 & $-150,24$ \\
\hline-4 & $-10,2$ & 150 & $-150,35$ \\
\hline .5 & $-12,3$ & 150 & $-150,50$ \\
\hline-6 & $-15,3$ & 150 & $-150,78$ \\
\hline .7 & $-17,8$ & 150 & $-151,05$ \\
\hline-8 & $-21,1$ & 150 & $-151,48$ \\
\hline-9 & -23 & 150 & $-151,75$ \\
\hline-10 & -26 & 150 & $.152,24$ \\
\hline
\end{tabular}


Tabel 5 Perhitungan Standar deviasi

\begin{tabular}{ccc}
\hline$N_{0 .}$ & $c$ & $c^{2}$ \\
\hline 1 & 152,59 & 23283,71 \\
2 & 152,07 & 23125,28 \\
3 & 151,00 & 22982,56 \\
4 & 151,26 & 22879,59 \\
5 & 151,02 & 22807,04 \\
6 & 150,61 & 22683,37 \\
7 & 150,44 & 22632,19 \\
8 & 150,24 & 22572,06 \\
9 & 150,15 & 22545,02 \\
10 & 150,03 & 22509 \\
11 & 150 & 22500 \\
12 & 150,02 & 22506 \\
13 & 150,10 & 22530,01 \\
14 & 150,24 & 22572,06 \\
15 & 150,35 & 22605,12 \\
16 & 150,50 & 22650,25 \\
17 & 150,78 & 22734,01 \\
18 & 151,05 & 22816,1 \\
19 & 151,48 & 22946,19 \\
20 & 151,75 & 23028,06 \\
21 & 152,24 & 23177,02 \\
$10+101$ & 3168,52 & 478085,2 \\
\hline & &
\end{tabular}

\section{Perhitungan Standar deviasi}

$$
\begin{aligned}
& \left(n \sum_{i=1}^{n} x_{i}\right)^{2}=3168,52^{2}=10.039 .518,9 \\
& s^{2}=\frac{n \sum_{i=1}^{n} x_{i}^{2}-\left(n \sum_{i=1}^{n} x_{i}\right)^{2}}{n(n-1)} \\
& s^{2}=\frac{(21) \times(478.085,2)-(10.039,518,9)}{21(20)} \\
& s^{2}=\frac{10.039,789,2-10.039 .518,9}{420} \\
& s^{2}=\frac{270,3}{420} \\
& s^{2}=0,64 \\
& s=\sqrt{0,64} \\
& s=0,8
\end{aligned}
$$

Jadi, nilai standar deviasi pada perhitungan sudut terhadap jarak sebenarnya adalah 0,8 .

\section{KESIMPULAN}

Berdasarkan hasil pengujian dan analisa menggunakan metode trial and error dapat diperoleh kesimpulan sebagai berikut:

1) Sistem gerak senjata dibuat dengan sistem mekanik yang memiliki resolusi sudut sebesar $0.08^{\circ}$. Sedangkan, jangkauan maksimum dari alat yang didapatkan pada sudut $10^{\circ}$ dan $+10^{\circ}$ sebesar $-152,24 \mathrm{~cm}$ dan $152,59 \mathrm{~cm}$. persentase error kontrol posisi sudut sebesar $1,38 \%$ dan nilai standar deviasi yang didapatkan dari perhitungan nilai sudut terhadap jarak sebenarnya adalah 0,8 .

2) Metode yang cocok dalam penjejakan target adalah color pattern recognition. Karena memiliki respon yang cepat dalam mecocokan gambar yang nyata dengan template yang telah dibuat.

3) Sistem Kontrol Posisi Sudut yang sesuai adalah Kontrol PD (Proportional Derivative) dengan nilai $\mathrm{Kc}=10, \mathrm{Ti}=0$, dan $\mathrm{Td}=1 \times 10^{-6}$ dengan besar waktu untuk mencapai set point (sp) sebesar 4,7 detik.

\section{DAFTAR PUSTAKA}

[1.] Syarief, Syafrizal. 2015. "Pengukuran Overall Equipment Effectiveness(OEE) Dengan LabVIEW 8.5 Sebagai Pengendali Maintenance”. Jurnal Politeknologi Vol.14 No.2, Mei 2015.

[2.] Syarief, Syafrizal. 2016. "Sistem Monitoring Suhu dan Kelembaban Tanaman Cabai pada Greenhouse Berbasis LabVIEW". Jurnal Politeknologi Vol.14 No.2, Mei 2016. 
[3.] .Andre, Julfikar Ali. 2016. "Sistem Security Webcam dengan menggunakan Microsoft Visual Basic (6.0)”. Jurnal Teknologi dan Sistem Informasi UNIVRAB, Vol. 1, No. 2, ISSN : 2477-2062.

[4.] Bolton, W. Instrumentation And Control System. Penerbit Erlangga, Jakarta, 2006

[5.] Horrocks, D.H., 1985, Feedback Circuits and Op. Amps., England : Van Nostrand Reinhold (UK) Co. Ltd, Chap. 6, 97 - 114.

[6.] Irianto, Suhendro Y. 2016. "Analisa Citra Digital dan Content Based Image Retrieval”. Lampung : CV. Anugerah Utama Raharja (AURA).

[7.] Kehtarnavaz, Nasser. Dkk. 2016. "Journal of Real-Time Image Processing”. Vol. 11, No. 3.

[8.] Logitech. "The Logitech Webcam C930e”. Tahun Publikasi: 2014, https://www.logitech.com/assets/4 7868/logitech-webcam-c930edata- sheet.pdf, (Diakses15 Desember 2017)

[9.] M. S. Rahmat, K. Hudha, A. M. Idris dan N. H. Amer. 2016. "Sliding Mode Control of Target Tracking System for Two Degrees of Freedom Gun Turret Model”. Advances in Military Technology. Vol. 11, No. 1.

[10.] National Instrument. USB-6351. Diakses 7 Desember 2017. http://ni.com/enid/support/model.usb-6351.html

[11.] .Nedivi, Lior. 2012. "Proof of NonLethality of Airsoft Guns". AFTE Journal. Vol. 44 No. 2. 
Syafrizal Syarief dan Fhyras Ayatullah Rismawa, Autonomous Target Tracking... 